\title{
Pulmonary edema after shoulder arthroscopy in an old female under general anesthesia
}

\author{
Fei $\mathrm{LIN}^{1+}$, Qihai WAN ${ }^{1+}$, Gang ZHANG ${ }^{2} \mathrm{Li} \mathrm{SU}^{2}$, Chunqiong LUO ${ }^{2}$, Yunhua SHUI ${ }^{2}$, Si ZENG ${ }^{3}$, Lan $\mathrm{ZHANG}^{2}$ (D)
}

\begin{abstract}
A number of complications have been ascribed to shoulder arthroscopy, but pulmonary edema is rarely reported. A 64-yearold female underwent right shoulder arthroscopic repair for supraspinatus and subscapular tears under intermuscular sulcus brachial plexus block (ISBPB) and general anesthesia. Finishing suture of torn tendon, and acromion and distal clavicle plasty, the patient represented the symptoms of dyspnea, and oxygen saturation quickly dropped to $80 \%$ without oxygen supply. After inhaled oxygen, the oxygen saturation quickly returned to 95\%, while dyspnea didn't improve. Noticing swelling in neck and chest, left movement of the trachea, low breath sounds and wet rales during auscultation, ultrasound examination was performed and found the obvious pleural slip, and a large number of b-lines in the lung, indicating pulmonary edema. After injection of furosemide and dexamethasone (i.v.), the outcome of patient was satisfactory. This is the first report of pulmonary edema as a complication of shoulder arthroscopy, which also reviews the relevant factors of fluid extravasation, and highlights the good use of the equipment at hand to quickly judge the patient's condition.
\end{abstract}

Keywor: ultrasound, shoulder arthroscopic surgery, pulmonary edema, B-line, Furosemide.

Practical Application: For shoulder arthroscopic surgery, we need to consider pulmonary edema. This complication should alert surgeons to maintain vigilance during and after surgery and preventively intervene if necessary.

\section{Introduction}

Surgical treatment is recommended for some shoulder diseases which cannot be cured by conservative management, specially rotator cuff tears. Shoulder arthroscopy is considered as a minimally invasive technique and popular in clinic treatment for its small trauma, fast postoperative recovery and safety (Paxton et al., 2013). Shoulder arthroscopy has some special complications such as neck and chest swelling as well as respiratory obstruction (Blumenthal et al., 2003; Ercin et al., 2016) caused by fluid extravasation, but pulmonary edema is extremely rare, which is a serious complication that can be life-threatening. Although infrequent, cases of negative pressure pulmonary edema following shoulder arthroscopy or other types of arthroscopy have been reported (Mamaril \& Zeltt, 1997; Gogia et al., 2012).

Hereby, we reported a case of a 64-year-old female who suffered pulmonary edema mainly due to fluid extravasation and airway obstruction after shoulder arthroscopy. This case demonstrates the complication development of pulmonary edema, reviews the relevant factors of fluid extravasation, and highlights the importance of good use of the equipment at hand to quickly judge the patient's condition.

This study was approved by The Ethics Committee of Sichuan Provincial Orthopedic Hospital (2019SGKL00401). Participant have provided their written informed consent to participate in this study.

\section{Case report}

A female 64 year-old, $45 \mathrm{~kg}$ weight, $145 \mathrm{~cm}$ height, American Society of Anesthesiologists physical status class II, underwent right shoulder arthroscopic repair for supraspinatus and subscapular tears. The preoperative evaluation showed no history of surgery or allergies, no abnormality in chest radiographs and Electrocardiograph (ECG), proper numerical ranges in laboratory examinations. The patient was classified as Mallampati class II and gave her written informed consent for the procedure.

During routine monitoring (ECG, pulse oximetry, axillary temperature, noninvasive and invasive blood pressure), the intermuscular sulcus brachial plexus block (ISBPB) was performed under the guidance of nerve stimulator combined with ultrasound. $30 \mathrm{ml}$ of $0.33 \%$ ropivacaine was used for nerve block. Midazolam $1 \mathrm{mg}$, propofol $80 \mathrm{mg}$, sufentanil $20 \mathrm{ug}$ and rocuronium $30 \mathrm{mg}$ were used to induce general anesthesia, and a mixture of sevoflurane, oxygen, and air was used to maintenance. The patient was placed in the left lateral position after the fixation of tracheal tube under the visual laryngoscope. Microscopic findings revealed tears of the superior scapularis and subscapularis muscles, hyperplasia of the anterior acromion and distal clavicle. The torn tendon was sutured, acromion and distal clavicle plasty were performed. The intravenous fluids of $1000 \mathrm{ml}$, including crystal fluid of $500 \mathrm{ml}$ (Lactated Ringers) and colloid fluid of $500 \mathrm{ml}$ (Hydroxyethyl starch), were administered 
during the operation. A total of 30L of normal saline was used to irrigating the joint cavity during the 122 minutes of endoscopic operation. Surgery and anaesthesia lasted 150 minutes and 180 minutes respectively.

After the operation, the patient was placed back to the supine position, and the endotracheal tube was pulled out. However, when transferred to the recovery room, the patient complained of difficult breathing, neck and chest compression, and oxygen saturation quickly dropped to $80 \%$ without oxygen supply. Immediately, the patient was placed in a supine position with a high head and inhaled oxygen through the mask $(5 \mathrm{~L} / \mathrm{min})$. Meanwhile, the video laryngoscope and intubation box were prepared. Fortunately, within one minute, the patient's oxygen saturation quickly returned to $95 \%$, but the symptoms of dyspnea didn't improve significantly. Noticing significant swelling in neck and chest (Figure 1), low breath sounds and wet rales during auscultation, we realized that the cervical chest edema caused the respiratory compression. The ultrasound examination unexpectedly found the patient's pleural slip was obvious, a large number of $b$-lines in the anterior and lateral lungs of the chest wall (Figure 2A), indicating pulmonary edema. In addition, the patient had a large amount of effusion in the neck and chest, significantly increased soft tissue thickness, and the trachea was pushed to the left by neck swelling. Two hours after injection of furosemide $10 \mathrm{mg}$ and dexamethasone $10 \mathrm{mg}$ (i.v.), the urine volume exceeded $1500 \mathrm{ml}$, and the symptoms of dyspnea as well as neck and chest compression completely disappeared with the reduction of neck and chest edema. Pulmonary ultrasonography showed that the $\mathrm{B}$ lines reduced significantly (Figure $2 \mathrm{~B}$ ), and the trachea position was restored. Arterial blood gas analysis: $\mathrm{PH}: 7.38, \mathrm{PCO} 2: 41 \mathrm{mmHg}, \mathrm{PO} 2: 65 \mathrm{mmhg} \mathrm{K}+: 3.1 \mathrm{mmol} / \mathrm{L}$, $\mathrm{Na}+: 141 \mathrm{mmol} / \mathrm{L}, \mathrm{HCO} 3-: 24.3 \mathrm{mmol} / \mathrm{L}, \mathrm{HGB}: 118 \mathrm{~g} / \mathrm{L}$. Oxygen saturation was maintained at $94-95 \%$ without oxygen support. She was then taken back to the ward for further observation and treatment.

For further observation and treatment, the patient was taken back to the ward, and her vital signs were stable under oxygen and ECG monitoring. A bedside chest radio-graph showed the extravascular lung water has been absorbed, and the cardiothoracic ratio was normal except swelling of the soft tissue on the right chest wall. Follow-up revealed that subcutaneous edema and pulmonary ultrasound b-line disappeared completely after 24 hours (Figure 2C). Patient discharged smoothly after one week.
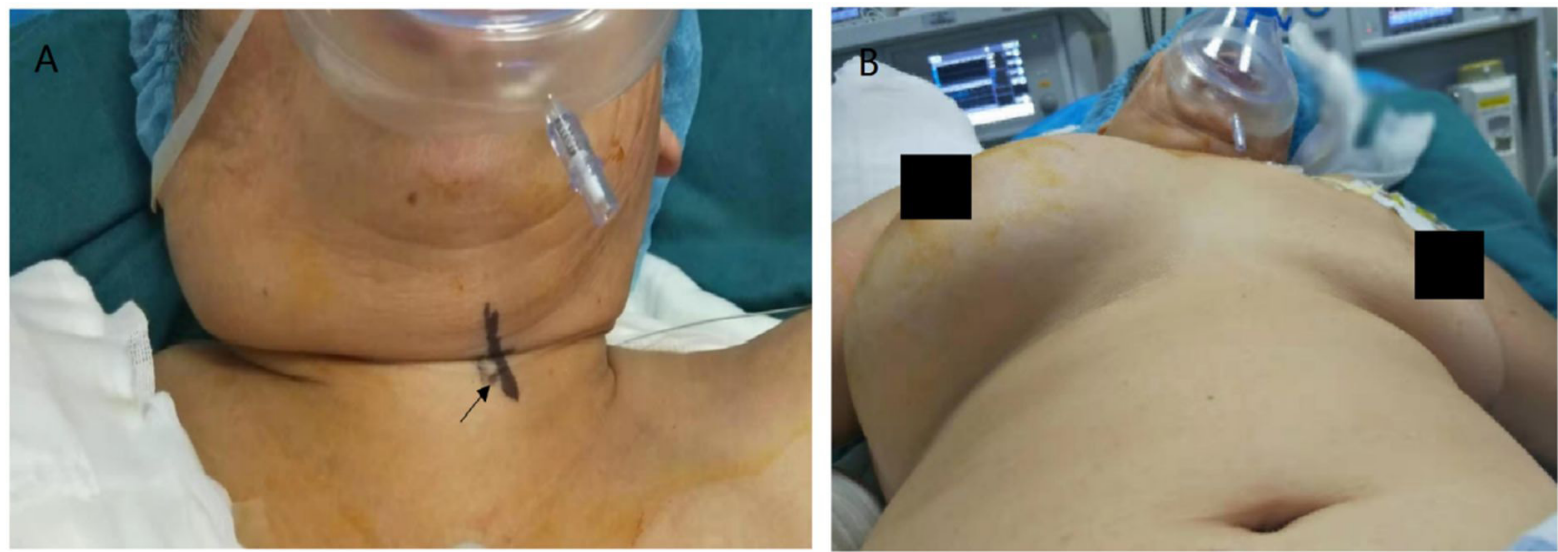

Figure 1. Swelling in neck and chest after shoulder arthroscopy. (A) Swelling in neck, and the trachea was pushed to the left by neck swelling (arrow); (B) Swelling in chest.
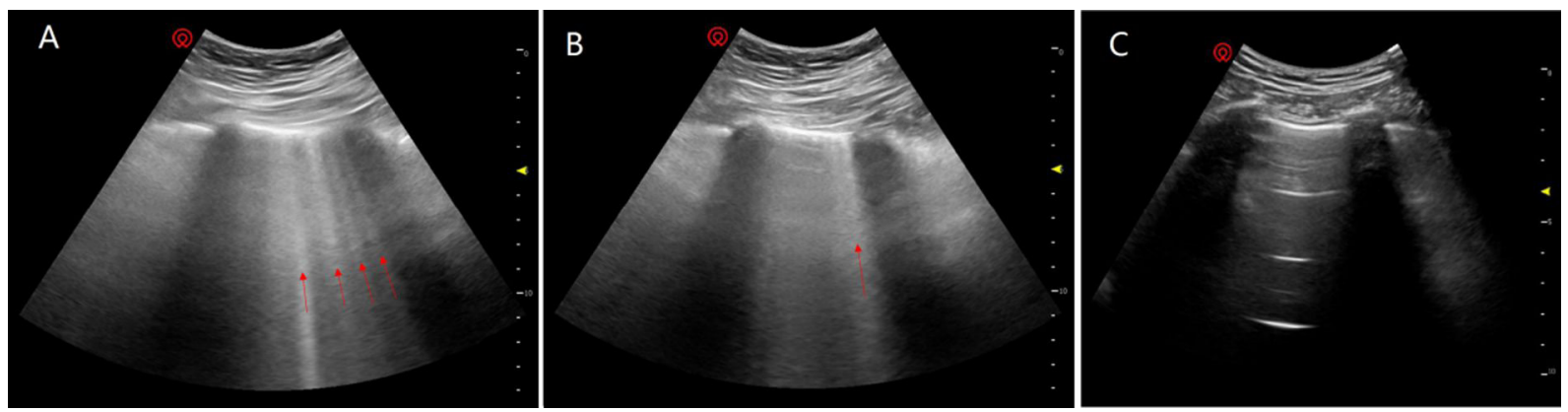

Figure 2. Ultrasonic images of the anterior chest wall and lung in different time points. (A) Ultrasonic images immediately after surgery; (B) Ultrasonic images $2 \mathrm{~h}$ after surgery; (C) Ultrasonic images $24 \mathrm{~h}$ after surgery. 


\section{Discussion}

In shoulder arthroscopy, a continuous positive pressure of the fluid is required to flush the joint cavity to provide a clear surgical field of view and reduce bleeding, which causes fluid extravasation. In most cases, extravasated fluids can be reabsorbed within 24 hours and won't cause significant clinical symptoms. However, extraarticular leakage can cause a number of complications, including edema, associated tracheal compression and airway obstruction, even respiratory impairment such as pulmonary edema (Memon et al., 2018). A review of previous reports shows that relevant factors for massive extravasation of fluid may include prolonged surgery, large irrigation fluid, high flushing pressure, subacromial operation, obesity, loose subcutaneous soft tissue, lateral recumbent position: (1) gain weight after shoulder arthroscopy is directly proportional to the amount of fluid used and duration of the operation (Smith \& Shah, 2008). (2) obese patients are more likely to exude flushing fluid through soft tissue around the joints because adipose layers are widely dispersed. (3) the spread of irrigation fluid is more due to the relaxation of skin and subcutaneous tissue in the elderly. (4) the fluid is more susceptible to extravasation during subacromial surgery since the subacromial gap is not completely wrapped (Matthews \& Fadale, 1989). (5) The lateral position may result in exosmosis of fluid that spreads downward to the neck due to gravity. Besides, automated pump system, anatomical abnormalities, iatrogenic injuries and doctor's experience are also related to intraoperative fluid extravasation. Soft tissue edema occurs more often when the patients had a damaged supraspinatus muscle or iatrogenic damage on the deltoid muscle (Edwards et al., 2014; Borgeat et al., 2000). Automated pump system causes more fluid retention than gravity flow system when used for equal duration of similar procedures in shoulder arthroscopy (Çatal \& Azboy, 2019). And the higher pressures and larger volumes of irrigation fluid are required to improve vision due to surgeon's limited experience. Reviewing the surgical procedures in our case, the severe neck and chest edema were mainly attributed to prolonged subacromial operations, torn muscles, large amounts of irrigation fluid, loose subcutaneous tissue, and a lateral position. In addition, for elderly patients undergoing orthopedic surgery, appropriate perioperative nutritional support also can reduce surgical complications and shorten recovery time (Hirsch et al., 2021). A study suggests that preoperative polyunsaturated fatty acids supplementation can reduce risk of postoperative complications caused by oxidative stress (Kubo et al., 2021).

Although we have considered the compression caused by swelling and the possibility that ISBPB might lead to pneumothorax and phrenic nerve block, the development of pulmonary edema was unanticipated. Ultrasound has been widely used in emergency and intensive care units to evaluate pulmonary edema. In pulmonary ultrasonography, the number of b-lines is even more sensitive than X-ray to assess the severity of pulmonary edema and can be detected in the subclinical stage before the clinical manifestations of pulmonary edema appear (Wooten et al., 2019; Blanco \& Cianciulli, 2016). It is important to note that pulmonary ultrasound b-line may appear in patients with pneumonia, pulmonary fibrosis, pulmonary consolidation, and pulmonary hemorrhage, but preoperative $\mathrm{X}$-ray results can rule out these possibilities. According to the number of b-lines, our patient developed severe pulmonary edema, which might be caused by a number of reasons. Firstly, a large amount of extravasation of fluid occurred in the surrounding soft tissue during the operation, and some of the fluid will be absorbed into the blood resulting in increased circulation capacity. Secondly, the patient with chest and tracheal compressions caused incomplete airway obstruction. When breathing hard, negative pressure of the chest increased, and venous return was promoted to increase pulmonary arterial pressure. Thirdly, hypoxia and an increase of negative pressure in the chest caused a decrease of cardiac output, which further increased the pressure on the pulmonary veins and microvessels. Therefore, the increased hydrostatic pressure of the lungs could lead to the entrance of the fluid to the interstitial lung, and the increase of extravascular lung water is manifested as pulmonary edema. For postoperative pulmonary edema, nutritional support also helps to promoting the respiratory function recovery (Saguil \& Fargo, 2020). For example, the application of antioxidants and anti-inflammatory food can reduce acute pulmonary edema, prevent the development of pulmonary complications and promote the recovery of patients (Ni et al., 2019; Uckun et al., 2020).

Reported cases have increased our vigilance against intraoperative and postoperative respiratory obstruction. However, few people pay attention to the circulation and lungs of patients. The reabsorption of extravasated fluids can have serious consequences for the elderly, children and patients with poor cardiac function, such as pulmonary edema in our case. Some researchers suggest that patients with severe postoperative neck and chest swelling and decreased oxygen saturation should receive timely chest X-ray examination to rule out pneumothorax (Kim et al., 2017). We think it is also necessary to help judge pulmonary edema, and the combination of pulmonary ultrasonography and chest X-ray will be better.

\section{Conclusion}

For shoulder arthroscopic surgery, we need to be familiar with the relevant factors of fluid extravasation and its possible complications. In addition to airway obstruction, pulmonary edema should be considered, especially for patients with more risk factors for fluid extravasation. This case report firstly demonstrates a serious complication of pulmonary edema that arise after shoulder arthroscopy. Review of this complication should alert surgeons to maintain vigilance during and after surgery and preventively intervene if necessary. Besides, good use of the equipment at hand can be helpful to quickly judge the patient's condition, such as ultrasound, fluoroscopy.

\section{Funding}

Funded by scientific research Fund of Sichuan Science and Technology Department Name: Study on clinical pathway of anesthesia for shoulder arthroscopy. No.: 20ZDYF1325.

\section{References}

Blanco, P. A., \& Cianciulli, T. F. (2016). Pulmonary edema assessed by ultrasound: impact in cardiology and intensive care practice. 
Echocardiography, 33(5), 778-787. http://dx.doi.org/10.1111/ echo.13182. PMid:26841270.

Blumenthal, S., Nadig, M., Gerber, C., \& Borgeat, A. (2003). Severe airway obstruction during arthroscopic shoulder surgery. Anesthesiology, 99(6), 1455-1456. http://dx.doi.org/10.1097/00000542-20031200000033. PMid:14639164.

Borgeat, A., Bird, P., Ekatodramis, G., \& Dumont, C. (2000). Tracheal compression caused by periarticular fluid accumulation: a rare complication of shoulder surgery. Journal of Shoulder and Elbow Surgery, 9(5), 443-445. http://dx.doi.org/10.1067/mse.2000.109320. PMid:11075331.

Çatal, B., \& Azboy, I. (2019). Fluid retention after shoulder arthroscopy: gravity flow vs. automated pump-a prospective randomized study. Journal of Shoulder and Elbow Surgery, 28(10), 1911-1917. http:// dx.doi.org/10.1016/j.jse.2019.05.041. PMid:31401126.

Edwards, D. S., Davis, I., Jones, N. A., \& Simon, D. W. (2014). Rapid tracheal deviation and airway compromise due to fluid extravasation during shoulder arthroscopy. Journal of Shoulder and Elbow Surgery, 23(7), e163-e165. http://dx.doi.org/10.1016/j.jse.2014.03.006. PMid:24929747.

Ercin, E., Bilgili, M. G., Ones, H. N., \& Kural, C. (2016). Postoperative pectoral swelling after shoulder arthroscopy. Joints, 3(3), 158-160. PMid:26889473.

Gogia, A. R., Bajaj, J., Sahni, A., \& Saigal, D. (2012). Negative-pressure pulmonary oedema in a patient undergoing shoulder arthroscopy. Indian Journal of Anaesthesia, 56(1), 62-65. http://dx.doi.org/10.4103/00195049.93347. PMid:22529423.

Hirsch, K. R., Wolfe, R. R., \& Ferrando, A. A. (2021). Pre- and postsurgical nutrition for preservation of muscle mass, strength, and functionality following orthopedic surgery. Nutrients, 13(5), 1675. http://dx.doi.org/10.3390/nu13051675. PMid:34063333.

Kim, J. B., Choi, M. K., Jeon, Y. K., \& Lee, J. M. (2017). Chest wall swelling and pneumothorax after shoulder arthroscopy: Were the 2 events totally independent? Medicine, 96(21), e7020. http://dx.doi. org/10.1097/MD.0000000000007020. PMid:28538422.

Kubo, Y., Ikeya, M., Sugiyama, S., Takachu, R., Tanaka, M., Sugiura, T., Kobori, K., \& Kobori, M. (2021). Association between preoperative long-chain polyunsaturated fatty acids and oxidative stress immediately after total knee arthroplasty: a pilot study. Nutrients, 13(6), 2093. http://dx.doi.org/10.3390/nu13062093. PMid:34205251.
Mamaril, M. E., \& Zeltt, K. E. (1997). Care of the arthroscopy patient with noncardiogenic pulmonary edema. Orthopedic Nursing, 16(2), 63-66. PMid:9155415.

Matthews, L. S., \& Fadale, P. D. (1989). Subacromial anatomy for the arthroscopist. Arthroscopy, 5(1), 36-40. http://dx.doi.org/10.1016/07498063(89)90088-1. PMid:2706049.

Memon, M., Kay, J., Gholami, A., Simunovic, N., \& Ayeni, O. R. (2018). Fluid extravasation in shoulder arthroscopic surgery: a systematic review. Orthopaedic Journal of Sports Medicine, 6(5), 2325967118771616. http://dx.doi.org/10.1177/2325967118771616. PMid:29785406.

Ni, Y. L., Shen, H. T., Su, C. H., Chen, W. Y., Huang-Liu, R., Chen, C. J., Chen, S. P., \& Kuan, Y. H. (2019). Nerolidol suppresses the inflammatory response during lipopolysaccharide-induced acute lung injury via the modulation of antioxidant enzymes and the AMPK/Nrf-2/HO-1 pathway. Oxidative Medicine and Cellular Longevity, 2019, 9605980. http://dx.doi.org/10.1155/2019/9605980. PMid:31827712.

Paxton, E. S., Backus, J., Keener, J., \& Brophy, R. H. (2013). Shoulder arthroscopy: basic principles of positioning, anesthesia, and portal anatomy. The Journal of the American Academy of Orthopaedic Surgeons, 21(6), 332-342. PMid:23728958.

Saguil, A., \& Fargo, M. V. (2020). Acute Respiratory Distress Syndrome: diagnosis and management. American Family Physician, 101(12), 730-738. PMid:32538594.

Smith, C. D., \& Shah, M. M. (2008). Fluid gain during routine shoulder arthroscopy. Journal of Shoulder and Elbow Surgery, 17(3), 415-417. http://dx.doi.org/10.1016/j.jse.2007.10.003. PMid:18276168.

Uckun, F. M., Carlson, J., Orhan, C., Powell, J., Pizzimenti, N. M., van Wyk, H., Ozercan, I. H., Volk, M., \& Sahin, K. (2020). Rejuveinix shows a favorable clinical safety profile in human subjects and exhibits potent preclinical protective activity in the LipopolysaccharideGalactosamine mouse model of Acute Respiratory Distress Syndrome and multi-organ failure. Frontiers in Pharmacology, 11(1), 594321. http://dx.doi.org/10.3389/fphar.2020.594321. PMid:33244300.

Wooten, W. M., Shaffer, L. E. T., \& Hamilton, L. A. (2019). Bedside ultrasound versus chest radiography for detection of pulmonary edema: a prospective cohort study. Journal of Ultrasound in Medicine, 38(4), 967-973. http://dx.doi.org/10.1002/jum.14781. PMid:30280401. 